\section{Comparison of hypertonic saline-sodium hydroxide method with modified Petroff's method for the decontamination and concentration of sputum samples}

\author{
Chaudhary SK, ${ }^{*}$ Mishra B ${ }^{2}$
}

1Department of Microbiology, Gandaki Medical College Teaching Hospital and Research Center,

Pvt. Ltd., Pokhara, Nepal; ${ }^{2}$ Department of Microbiology, St. John's Medical College and Hospital, Bangalore, India

*Correspondence to: Mr. Sushil Kumar Chaudhary, Department of Microbiology, Gandaki Medical College Teaching Hospital and Research Center, Pvt. Ltd., Pokhara, Nepal, e-mail: sushilkc2011@ gmail.com, Tel. No.: (+977)-9807512010

\begin{abstract}
INTRODUCTION: Tuberculosis is one of the major health problems particularly in developing countries. For definitive diagnosis of pulmonary tuberculosis identification of tubercle bacilli in sputum by microscopy and culture is essential. For decontamination and concentration of sputum, the commonly used method in the laboratory is Modified Petroff's method but the Hypertonic saline-sodium hydroxide (HS-SH) method is known to be better for detection of Mycobacterium tuberculosis by culture. This study was aimed to compare a novel method for the improvement of decontamination and concentration of sputum samples.
\end{abstract}

MATERIALS AND METHODS: A total of 50 confirmed smear positive sputum samples from pulmonary TB patients who visited at St. John's Medical College and Hospital during 2009 to 2010, were processed for the decontamination process. Each sample was decontaminated by Modified Petroff's and HS-SH method separately. Treated samples were cultured in Lowenstein-Jensen media in microbiology laboratory.

RESULTS: The culture positive percents of Mycobacterium tuberculosis in the L-J medium treated with HS-SH and Modified Petroff's method were $84.0 \%$ and $70.0 \%$, respectively. A notable feature is that by HS-SH method more samples were positive by $4^{\text {th }}$ week, statistically significant (Chi- square value-11.26 with $p$-value < 0.05) compare to Modified Petroff's method. The difference for $3+$ grades of L-J growths found slightly higher by Modified Petroff's method but at lower grades of growths HS-SH method performed better.

CONCLUSIONS: HS-SH method is better for the detection of Mycobacterium tuberculosis by culture when compared with the Modified Petroff's method.

KEY WORDS: Decontamination, Hypertonic saline sodium hydroxide method, Mycobacterium tuberculosis, Modified Petroff's method.

Article submitted 10 July. Reviewed 20 July. Author correction 28 July. Final version accepted 18 August 2013. 


\section{INTRODUCTION}

Tuberculosis is one of the major cause of death worldwide, especially in under developed countries. Currently about 10 million new cases of tuberculosis every year with 3 million deaths world wide. ${ }^{1}$ Identification of tubercle bacilli in sputum by microscopy as well as in culture is essential for definitive diagnosis of pulmonary tuberculosis. ${ }^{2}$ In developing countries diagnosis of acid fast bacilli is performed by microscopic examination of ZiehlNeelsen (Z-N) stained sputum smears, because it is simple, inexpensive and provide rapid results. But, this technique has a low sensitivity $(22-43 \%)$ for single smear 3 and up to $60 \%$ under optimal conditions ${ }^{4}$ when compared with cultures so that culture remains as gold standard to diagnose tuberculosis.

Modified Petroff's method is a feasible method for decontamination and concentration of sputum but kills $60-70 \%$ of the mycobacteria which could be due to higher concentration of $\mathrm{NaOH}(4 \%),{ }^{5}$ while in Hypertonic saline sodium hydroxide (HS-SH) method only $1.3 \% \mathrm{NaOH}$ (at final concentration w/v in $6 \mathrm{ml}$ ) is used for decontamination. ${ }^{6}$ Ganoza et al reported that the HS-SH method has higher sensitivity for culture (95.2\%) than NALC- $\mathrm{NaOH}$ method(76.2\%) which is one of the most adapted method for automated culture technique. ${ }^{6}$ Hence there is a need to assess the efficiency of HS-SH method with Modified Petroff's method for manual culture technique.

\section{MATERIALS AND METHODS}

A comparative study was carried out in the Microbiology Laboratory at St. John's Medical College and Hospital, Bangalore, India during March 2009- April 2010. Total of 50 consecutive sputum samples collected from pulmonary tuberculosis patients showing Ziehl-Neelsen stained smear positive as well as not falling under exclusion criteria with any history of anti-tubercle drug treatment, inadequate sample less than $2 \mathrm{ml}$, saliva only (without purulent material) were collected after a verbal consent from the patients who had visited our hospital for diagnosis and treatment. All samples were concentrated and decontaminated by Modified Petroff's Method 5 and Hypertonic SalineSodium Hydroxide Method $(2 \mathrm{ml}$ of sputum sample mixed with $2 \mathrm{ml}$ of $7 \% \mathrm{NaCl}$ and $2 \mathrm{ml}$ of $4 \% \mathrm{NaOH}$, followed by homogenization, incubation, neutralization and centrifugation). ${ }^{6}$ Immediately after the decontamination and concentration process, $200 \mu \mathrm{l}$ each re-suspended pellet were inoculated into two L-J media and incubated at $37^{\circ} \mathrm{C}$ and growth in medium was observed weekly for eight weeks. Mycobacterium tuberculosis isolates were identified using the following criteria: time to visible growth, colony pigmentation and morphology, AFB smear (Kent \& Kubica, 1985). Grading of the primary culture growth was done as per the guide line of Nantional Tuberculosis Institute, India. ${ }^{7}$

The collected data was collected and analyzed using statistical software, SPSS version 16.0. Frequencies and proportions were reported and Chi-square test was used to analyze the significance of the difference across the groups. p-value $<0.05$ were considered statistically significant.

\section{RESULTS}

Out of 50 samples that were decontaminated and concentrated by both the methods and cultured in L-J media, 35(70\%) samples showed growth which was decontaminated by Modified Petroff's method, whereas $42(84 \%)$ samples showed growth by HSSH method. Though growth difference is $14 \%$ more in HS-SH method, there is no statistical significant (p-value 0.09).

From the 50 specimens graded for growth, Modified Petroff's method showed $3+$ grading in 11/35 (31\%) which was slightly more than HS-SH method $(11 / 42,24 \%)$. Four specimens $(4 / 35,11 \%)$ showed $2+$ by Modified Petroff's method and 8/42 specimens $(19 \%)$ showed $2+$ grade of growth by HS-SH method. Modified Petroff's method showed $1+$ grading of culture growth in $8 / 35(23 \%)$, actual colony count in $12 / 35(34 \%)$ whereas by HS-SH method 13/42 (31\%) cases found with $1+$ growth \& $10(24 \%)$ with actual colony counts. Total $15 / 50$ $(30 \%)$ of cases showed no growth by Modified Petroff's method and 8/50 (16\%) cases showed no growth by HS-SH method.

After inoculation the L-J media were incubated for 8 weeks, which were observed and recorded for growth (i.e. appearance of visible colonies on the L-J slant). In this study by HS-SH method $12 / 42$ $(28.5 \%)$ cases were found culture positive after $3^{\text {rd }}$ week , $11 / 42(26.1 \%)$ after $4^{\text {th }}$ week, $5 / 42(11.9 \%)$ after $5^{\text {th }}$ week, $4 / 42(9.5 \%)$ after $6^{\text {th }}$ week, $10 / 42$ (23.8\%) after $7^{\text {th }}$ week, whereas in case of Modified Petroff's method 2/35 (5.7\%) after $3^{\text {rd }}$ week, 18/35 $(51.4 \%)$ after $4^{\text {th }}$ week, $5 / 35(14.2 \%)$ after $5^{\text {th }}$ week, $6(17.1 \%)$ after $6^{\text {th }}$ week and $4 / 35$ (11.4) were found culture positive after $7^{\text {th }}$ week. The difference of growth rate after $3^{\text {rd }}$ week $28.5 \%$. 
by HS-SH method and 5.7\% by Modified Petroff's method is statistically significant. But the growth rate after $4^{\text {th }}$ week is higher in case of Modified Petroff's method.

\section{DISCUSSION}

To date culture is te gold standard technique for diagnosis of tuberculosis.6,8 For isolation of the tubercle bacilli in culture medium, contamination should be minimized and killing of tubercle bacilli should be avoided. ${ }^{7}$ To overcome these problems there should be use of a very convenient method to decontaminate and concentrate the specimen. Higher concentration of $\mathrm{NaOH}$ is used in Modified Petroff's method which kills 60-70\% mycobacteria ${ }^{5}$ whereas, in HS-SH method the concentration of $\mathrm{NaOH}$ used is low. ${ }^{6}$

In this study the culture positivity of the HS-SH (84\%) and Modified Petroff's method (70\%) are compared. The difference between cultures positivity by both methods are statistically not significant though more culture positivity with HSSH method was found. Christian A Ganoza et al. reported that the HS-SH method has higher sensitivity for culture $(95.2 \%)$ than NALC-NaOH method(76.2\%), 6 this study support the current finding with higher culture positivity rate by HSSH method. Similarly for the Modified Petroff's method, our result (70\%) corresponds with previous report by Keilty $66 \%{ }^{9}$ and Stewart $64 \% .^{10,11}$

In our study the overall contamination rates $(8 \%$ by Modified Petroff's 6\% by HS-SH on total L-J cultures) was as similar to those observed by others, ranging from 1.5 to $13.3 \% 12$ and $6.1 \%$ by Christian C.G. ${ }^{6}$ We noticed, better digestion of thick mucoid sputum with hypertonic saline than that of only $4 \% \mathrm{NaOH}$ used in Modified Petroff's method, could be the reason for higher culture positive result by HS-SH method. While comparing the grading of culture growth, 3+ grade was found slightly more in number by Modified Petroff's method whereas 2+ \& 1+ grade were found more with HS-SH method. During weekly observation of inoculated L-J media, the growth rate by HS-SH method was more by $4^{\text {th }}$ week in comparison to Modified Petroff's method. This is may be due to the presence of hypertonic saline as a mucolytic agent $^{13}$ which is responsible for better liquefaction of sputum samples by HS-SH method and the growth occurs faster in this method as compared to Modified Petroff's method.

Table 1. Comparison of grading of growth and culture positivity on L-J media

\begin{tabular}{|c|c|c|c|}
\hline S.N. & $\begin{array}{l}\text { Total growth on L-J media and } \\
\text { it's grading }\end{array}$ & $\begin{array}{l}\text { Modified Petroff's } \\
\text { Method }\end{array}$ & HS-SH Method \\
\hline 1. & $\begin{array}{l}\text { Total no. of samples } \\
\text { processed }\end{array}$ & $50(100 \%)$ & $50(100 \%)$ \\
\hline 2. & $\begin{array}{l}\text { Total no. of positive } \\
\text { cultures* }\end{array}$ & $35(70 \%)$ & $42(84 \%)$ \\
\hline 2.a & $3+$ & $11 / 35(31 \%)$ & $11 / 42(26 \%)$ \\
\hline 2.b & $2+$ & $4 / 35(11 \%)$ & $8 / 42(19 \%)$ \\
\hline 2.c & $1+$ & $8 / 35(23 \%)$ & $13 / 42(31 \%)$ \\
\hline 2.d & Actual colony count & $12 / 35(34 \%)$ & $10 / 42(24 \%)$ \\
\hline 3. & Contamination & $4(8 \%)$ & $3(6 \%)$ \\
\hline 4. & No growth & $11(22 \%)$ & $5(10 \%)$ \\
\hline
\end{tabular}

Table 2. Comparisons of growth rate by modified Petroff's and HS-SH method after inoculation of sputum on L-J media

\begin{tabular}{|c|c|c|c|}
\hline S.N. & Growth (week) & Modified Petroff's Method & HS-SH Method \\
\hline 1 & $4^{\text {th-}}$-week* & $2(5.7) \%$ & $12(28.5 \%)$ \\
\hline 2 & $5^{\text {th- }}$ week & $18(51.4 \%)$ & $11(26.1 \%)$ \\
\hline 3 & $6^{\text {th }}-$ week & $5(14.2 \%)$ & $5(11.9 \%)$ \\
\hline 4 & $7^{\text {th }}$ - week & $6(17.1 \%)$ & $4(9.5 \%)$ \\
\hline \multirow[t]{2}{*}{5} & $8^{\text {th }}$ - week & $4(11.4 \%)$ & $10(23.8 \%)$ \\
\hline & Total & $35(100 \%)$ & $42(100 \%)$ \\
\hline
\end{tabular}

\footnotetext{
${ }^{*}$ At $4^{\text {th }}$ week the difference in growth rate is statistically significant (Chi-square value- 11.26 with p-value less than 0.05 ).
} 


\section{Hypertonic saline-NaOH versus modified Petroff's method for the sputum decontamination}

\section{CONCLUSION}

Culture remains the gold standard for the accurate diagnosis of pulmonary tuberculosis. Here, we found that HS-SH method gives the better result for early recovery of Mycobacterium tuberculosis on culture. To assess the exact efficiency of culture positivity, growth rate, grading of growth on L-J and rate of contamination by HS-SH method more number of samples should be analyzed.

\section{ACKNOWLEDGEMENTS}

I express my sincere and heartfelt thanks to my guide, Dr. Baijayanti Mishra ,MD, Associate Professor, Department of Microbiology, St. John's Medical College and Hospital, Bangalore, India for the immense help, her valuable guidance, encouragement, commitment and timely support during course of this study and has enabled me to bring the work to completion. I am greatly indebted to Associate Professor Dr. Amar Nagila and Mr. Sudip Regmi, Gandaki Medical College Teaching Hospital, Pokhara for their guidelines to come up with this paper work.

CONFLICT OF INTEREST: None to declare.

FINANCIAL INTEREST: None to declare.

\section{REFERENCES}

1. Dye C, Scheele S, Pathania V, Raviglione MC. Global burden of tuberculosis estimated incidence and mortality by country. J Am Med Assoc 1999;282:677-687.

2. Vasanthkumari R. Concentrated sputum smears microscopy: A simple approach to better case detection in pulmonary tuberculosis. Indian J Tuberc 1988;35:80-85.

3. Toman K. Tuberculosis case-finding \& chemotherapy. case detection, treatment and monitoring-questions \& answers, $2^{\text {nd }}$ Ed. Geneva: WHO;2004.

4. Asper L, Mutsvangwa J, Magwenzi J, et al. A comparison of direct microscopy, the concentration method and the Mycobacteria Growth Indicator Tube for the examination of sputum for acid fast bacilli. Int J Tuberc Lung Dis 2003;7:376-381.

5. Kent PT, Kubica GP. Public Health Mycobacteriology a guide for the level III laboratory. Centre for Disease Control Manual. 1985;21-44.

6. Ganoza CA, Ricaldi JN, Chauca J, et al. Novel hypertonic saline- sodium hydroxide (HS-SH) method for decontamination and concentration of sputum samples for Mycobacterium tuberculosis microscopy and culture. J Med Microbiol 2008;57:1094-1098.

7. National Tuberculosis Institute. Primary culture technique and reading. In: manual on isolation, identification and sensitivity testing of Mycobacterium tuberculosis. $2^{\text {nd }}$ ed. 1998;15-23.

8. Grandjean L, Martin L. Gilman RH et al. Tuberculosis diagnosis and multi-drug resistance testing by direct sputum culture in selective broth without decontamination or centrifugation. J Clin Microbiol 2008;46;2339-2344.

9. Keilty RA. A study of the cultivation of the tubercle bacillus directly from the sputum by the method of Petroff. J Exp Med 1915;22:612-614

10. Stewart FC. A note on Petroff's culture method for the isolation of tubercle bacilli from sputum and its application to the examination of milk. J Exp Med 1917;26:755-761

11. Malkani M. The isolation of the Tubercle bacillus from sputum: A comparative study of Petroff's and of Corper \& Uyei's methods. Am Rev Tuberc 1929;19:47-54.

12. Somoskovi A, Magyar P. Comparison of the Mycobactaria Growth Indicator Tube with MB redox, Lowenstein - Jensen, and Middlebrook 7H11 media for recovery of mycobacteria in clinical specimen. J Clin Microbiol 1999;37:1366-1369.

13. Donaldson SH, Bennett WD, Zeman KL, et al. Mucus clearance and lung function in cystic fibrosis with hypertonic saline. N Engl J Med 2006;354:241-250.

\section{Citing this article}

Chaudhary SK, Mishra B. Comparison of Hypertonic saline-sodium hydroxide method with Modified Petroff's method for the decontamination and concentration of sputum samples. Int J Infect Microbiol 2013;2(3):78-81. 